\title{
Genetic Risk for Recurrent Urinary Tract Infections in Humans: A Systematic Review
}

\author{
M. Zaffanello, ${ }^{1}$ G. Malerba, ${ }^{2}$ L. Cataldi, ${ }^{3}$ F. Antoniazzi, ${ }^{1}$ M. Franchini, ${ }^{4}$ \\ E. Monti, ${ }^{1}$ and V. Fanos ${ }^{5}$ \\ ${ }^{1}$ Department of Mother-Child and Biology-Genetics, Section of Pediatrics, University of Verona, Piazzale L. Scuro, 10, \\ 37134 Verona, Italy \\ ${ }^{2}$ Department of Mother and Child and Biology-Genetics, Section of Biology and Genetics, University of Verona, Verona 37134, Italy \\ ${ }^{3}$ Division of Neonatology, Catholic University of the Sacred Heart, Rome 00168, Italy \\ ${ }^{4}$ Department of Pathology and Laboratory Medicine, Immunohematology and Transfusion Center, University Hospital of Parma, \\ Parma 43121, Italy \\ ${ }^{5}$ Neonatal Intensive Care Unit, University of Cagliari, Cagliari 09124, Italy
}

Correspondence should be addressed to M. Zaffanello, marco.zaffanello@univr.it

Received 31 July 2009; Accepted 25 February 2010

Academic Editor: Wenjiang J. Fu

Copyright ( $) 2010$ M. Zaffanello et al. This is an open access article distributed under the Creative Commons Attribution License, which permits unrestricted use, distribution, and reproduction in any medium, provided the original work is properly cited.

\begin{abstract}
Urinary tract infections (UTIs) are a frequent cause of morbidity in children and adults and affect up to $10 \%$ of children; its recurrence rate is estimated at $30-40 \%$. UTI may occur in up to $50 \%$ of all women in their lifetimes and frequently require medication. Recent advances have suggested that a deregulation of candidate genes in humans may predispose patients to recurrent UTI. The identification of a genetic component of UTI recurrences will make it possible to diagnose at-risk adults and to predict genetic recurrences in their offspring. Six out of 14 genes investigated in humans may be associated with susceptibility to recurrent UTI in humans. In particular, the HSPA1B, CXCR1 \& 2, TLR2, TLR4, TGF- $\beta 1$ genes seem to be associated with an alteration of the host response to UTIs at various levels.
\end{abstract}

\section{Background}

Urinary tract infections (UTIs) are a frequent cause of morbidity in children and adults. UTIs affect up to $10 \%$ of the pediatric population [1] and the recurrence rate of UTI in children is estimated at $30 \%$ to $40 \%$, with the majority of recurrences occurring in the first 12 months after the initial infection $[2,3]$. Recurrent UTI is more frequent in very young females older than 6 months [4]. UTIs may occur in up to $50 \%$ of all women in their lifetimes and $10 \%-15 \%$ of cases require medication [5]. Susceptibility to recurrent UTIs in women could be the result of a combination of various risk factors such as periurethral bacterial colonization and Escherichia coli virulence [6].

The pathogenesis of recurrent UTIs consists of the three classic components of any infection: host, pathogen and environment [6]. The severity of a UTIs is determined by the innate defense mechanisms of the host and by the virulence of the infecting agents. The pathogenesis of the inflammation involves the recruitment of neutrophils into the urinary tracts and chemokines-chemokine receptor interactions. An inhibition of mucosal signaling creates a state of asymptomatic bacterial carriage (asymptomatic bacteriuria). Intricate molecular interactions govern pathogen recognition on mucosal surfaces as well as bacterial virulence. The innate host defense mechanisms determine the severity of infection [7].

For unknown reasons, UTIs are clustered in certain individuals. UTIs are more prevalent in female relatives of women with recurrent UTIs, which suggests a familial genetic predisposition to the disease [8-10]. Animal models have shown the multigenic nature of recurrent UTIs. Mouse models of induced, unobstructed UTI have been important in showing the influence of genetic factors on host susceptibility and resistance to bladder and kidney infections [11, 12]. Other studies on both experimental mice and humans 
have disclosed that a predisposition to UTIrecurrences could be inherited, suggesting that the increased susceptibility to UTI is a complex heritable trait influenced by several genes [13]. Putative candidate genes for the disease include genes that are involved in the antimicrobial defense of surface epithelia.

The objectives of this systematic review were to present the genetic knowledge on the susceptibility to UTI recurrences in humans.

\section{Methods}

Using electronic databases, we looked for suitable comparative studies on children and adults that investigated the genetic susceptibility to recurrent UTIs. Participants were individuals of either gender with known or unknown familial history of UTIs. UTIs occurred at both high (pyelonephritis) or low (cystitis) urinary tract levels. We excluded studies on animals. Clinical investigations for UTIs included microbiological urinalysis and instrumental investigations (ultrasound, voiding cystoureterogram and DMSA scintigraphy). We excluded studies enrolling patients with urinary tract obstruction. The included studies were aimed at obtaining allele and genotype frequencies of gene polymorphisms/mutations and gene expression of specific loci recognized/suspected to be involved in UTIs recurrences in both experimental patients and controls.

We searched the MEDLINE, SCOPUS and EMBASE sites from 1985 through July 2009. We did not research literature prior to 1985 because genes relating to UTIs recurrences only began to be investigated in animals from 1985 [14, 15]. The first study that suspected a genetic predisposition to UTI recurrences in both mice and humans was published in 2000 [16]. The MeSH terms and text words (and their combinations and truncated synonyms) were adapted as appropriate to search each database by combining the terms "urinary tract infection AND (genetic predisposition OR genetic susceptibility OR genetic variation OR genetic mutation OR genetic polymorphism) AND human." We also did a manual search of all the bibliographies from the selected studies and from relevant review articles.

In some of the selected studies, we retrieved the genotype frequency distribution for each gene polymorphism investigated in patients with recurrent UTIs and controls. We retrieved the odds ratio (OR) and the confidence interval $(95 \% \mathrm{CI})$ and/or the results of the statistical analyses ( $P$ values) that compared the frequency of gene polymorphisms between cases and controls. Moreover, we retrieved information on mRNA levels and the protein expression of candidate genes.

To our knowledge, no genome-wide association study has been done on a large sample of individuals to discover novel genetic caused susceptibility factors for UTIs. To date, association with UTI has been studied from a candidate gene approach only. The association between genetic variability and clinical susceptibility to disease often lacks definitive evidence due to methodological issues, high heterogeneity and deaths which preclude meta-analytical association studies [25]. It is also worth noting that the significant genetic associations reported could also include false positive results [26]. Thus, we investigated the methodological quality of each enrolled study. In particular, we looked to see if both genetic and protein expressions were investigated in the same study, if the ethnicity of the target population was reported, if the Hardy-Weinberg equilibrium was ascertained in both the case and control groups, if the authors declared any UTIs recurrence and the presence or not of a urinary tract malformation in their patients.

\section{Results}

Our initial search into the literature identified a large number of papers from PUBMED (236 found), SCOPUS (680) and EMBASE (80). After a hand screening for titles and abstracts, 21 studies were considered to be relevant to this review. A closer look at these 21 papers excluded 11 papers because they investigated the genetic susceptibility to renal damage after aUTI [27-37]. Finally, ten studies were identified from the literature as being eligible for this review [16-25]. Among them, two studies referred to the same protocol and patients $[13,16]$. Seven studies investigated the frequency of target gene polymorphisms in patients with recurrent UTIs $[17,18$, 20-24], one of which lacked a control group [20]. Moreover, five studies investigated the expression of mRNA or the proteins of candidate genes associated with UTI recurrence $[16,18-20,23]$. In summary, the nine studies we settled on included only an assessment of gene polymorphisms $[17,21,22,24]$, only mRNA or protein expression assessment $[13,16,19]$ or both $[18,20,23]$.

3.1. IL-8 Receptor CXCR1 and CXCR2 Genes. Frendéus et al. investigated the neutrophil CXCR1 and CXCR2 surface expressions in mice and humans. Twelve children with recurrent UTIs showed decreased expression of CXCR1 protein and mRNA levels in neutrophils of children prone to pyelonephritis [16]. CXCR2 expression was comparable between patients and controls [13]. Smithson et al. investigated the surface expression of CXCR1 and CXCR2 as well as the presence of CXCR1 gene polymorphisms in 20 premenopausal women with recurrent UTIs and normal urinary tracts and 30 females with no history of UTIs. CXCR1 expression was similar to that of healthy controls, whereas CXCR2 expression was lower than in controls. Sequence analysis of promoter and coding sequence of the CXCR1 gene showed the presence of three polymorphisms in the exon 2: one patient with R335C and two patients with S276T [20]. The study by Lundstedt et al. investigated the full-length CXCR1 gene sequence in 12 pediatric patients, 12 pediatric controls and 35 adults with childhood APN. The frequency of relevant CXCR1 gene polymorphisms was further assessed in 12 children, one adult, 14 control children, and 200 healthy adult blood donors. The novel $217 \mathrm{C}>\mathrm{G}$ polymorphism of the CXCR1 gene was located in a putative binding site for the run-related transcript factor 1 (RUNX1), which is required for expression from 
a number of cell specific enhancers and promoters. The allele $217 \mathrm{G}$ was observed to be associated with a reduction in RUNX1 binding. Moreover, aberrantly reduced CXCR1 mRNA processing from patients and mothers carrying the A allele of the $3665 \mathrm{G}>\mathrm{A}$ polymorphism suggested that this variant might create a more efficient cleavage site, reducing the amount of large CXCR1 mRNA. Moreover, the CXCR1 expression by flow cytometry in 60 patients ( 24 children and 36 adults) with a history of childhood UTIs and controls (26 children and 200 adults) showed low CXCR1 surface neutrophil expression in patients prone to APN [18]. In another paper, the same authors investigated the CXCR1 surface expression in 10 children with a history of APN and recurrent UTI, as well as their families, and 15 controls. CXCR1 expression was lower in the patients and their families compared to controls [19].

3.2. Heat Shock Protein 72 (HSPA1B) Gene. Karoly et al. investigated the frequency of the $1267 \mathrm{~A}>\mathrm{G}$ polymorphism of the heat shock protein 72 gene (HSPA1B) and the frequency of the TLR4 896A $>\mathrm{G}$ polymorphism in 103 children with recurrent UTIs compared with 235 randomly selected controls. Clinical investigations identified vesicoureteral reflux (VUR) in 50 patients and renal scarring in 40 patients, more commonly in those suffering from high-grade VUR. The $1267 \mathrm{G}$ allele occurred more frequently in patients with recurrent UTIs [17].

3.3. Toll-like Receptor (TLR) Pathway Genes. The 896/AG genotype and the $896 \mathrm{G}$ allele of the TLR4 gene showed a higher prevalence among UTI patients than among controls. Moreover, the 896/AG genotype and 896G allele tended to occur more frequently in patients with recurrent UTIs without VUR [17].

Ragnarsdóttir et al. investigated the TLR4 protein expression in 17 children with asymptomatic bacteriuria (ABU) and 24 controls. They found reduced expression of the TLR4 protein. The authors recruited 41 pediatric and 29 adult patients and age-matched controls, to measure single immunoglobulin domain-containing IL- 1 receptor-related molecule (SIGIRR) and TLR4 adaptor protein TRIF expressions (TIR domain containing adaptor inducing interferon$\beta$ ), TRAM (TRIF-related adaptor molecule) and MyD88 (Myeloid differentiation primary response gene 88). They found high levels of the TLR4 adaptor protein TRIF and reduced levels of the TLR4-inhibitor SIGIRR in the patients with ABU. They proceeded with DNA sequencing of TRL4 DNA in 28 children with ABU and 14 controls but they identified only one known missense mutation in one control subject. The TRIF gene was sequenced in 12 children and 11 controls. The frequency of TRIF polymorphisms was comparable between the patients with $\mathrm{ABU}$ and the control subjects [23].

Tabel et al. investigated the $2258 \mathrm{G}>\mathrm{A}$ polymorphism (also described in the paper as G2251A or rs5743708 referring to Arg753Gln: http://www.snpedia.com/ index.php/Rs5743708) of the TLR2 gene in 124 Turkish children with a first time or recurrent UTI. This study demonstrated a significantly higher frequency of the 2258A allele in the TLR2 gene in patients with recurrent UTIs than in 116 controls. The authors did not find any correlation between a TLR2 gene polymorphism and the localization of UTIs [22].

In a case-controlled designed study, Hawn et al. investigated the TLR pathway genes in 431 adult women with recurrent UTIs and 430 controls. Nine TLR pathway genes including TLR-1,2,4,5,6 and the genes of the TLR4 adaptor molecules MYD88, TIR domain containing adapter (TIRAP), TRIF, and TRAM, were sequenced at DNA level. In particular, 45 patients for the TLR2 gene, 43 for the TLR4 gene, 46 for the TLR5 gene, 86 for the TIRAP gene and 87 for the TRIF gene were investigated. The TLR5 $1174 \mathrm{C}>\mathrm{T}$ gene polymorphism was associated with increased susceptibility to recurrent cystitis. No significant difference in the frequency of the 2258A allele of the TLR2 gene was found between adult women with UTI, including urinary tract malformations (UTM), and controls. The TLR1 1805G $>$ T and TLR4 896A $>$ G polymorphisms were associated with protection from APN and recurrent cystitis, respectively [21].

3.4. VEGF and TGF- $\beta 1$. Yim et al. investigated vascular endothelial growth factor (VEGF) and TGF- $\beta 1$ gene polymorphisms with susceptibility to UTI. In particular, the authors investigated two polymorphisms of the VEGF gene $(460 \mathrm{~T}>\mathrm{C}$ and $405 \mathrm{G}>\mathrm{C})$ and three polymorphisms of the TGF- $\beta 1$ gene $(-509 \mathrm{C}>\mathrm{T},-800 \mathrm{G}>\mathrm{A}$ and $869 \mathrm{~T}>\mathrm{C})$. The overall number of patients was 79 , of which 48 patients had renal scars and 57 had VUR, and 89 were controls. An increased VEGF 460/CC, TGF- $\beta 1-509 / C C$, TGF- $\beta 1-800 /$ GG genotype frequency and decreased VEGF 460/TC, TGF- $\beta$-509/TT, TGF- $\beta 1-800 /$ GA genotype frequency were found in patients with UTI when compared with control groups, both including patients with VUR. Excluding patients with VUR, children with UTIs showed an increased frequency of TGF- $\beta 1$ $-509 / C C$ genotype when compared to a control group [24].

3.5. Summary of the Results. Table 1 summarizes the main characteristics of the studies. Fourteen genes were investigated, in particular 10 genes for one or more polymorphisms, and 7 genes for their mRNA levels or protein expression. Only two studies including CXCR1 and TRIF genes combined the assessment of both polymorphisms and protein expression in patients with and without VUR $[18,23]$. The majority of the studies included patients with VUR and the minority included different nonobstructive UTMs. Only two studies investigated CXCR1, CXCR2 protein expression and TLR2 polymorphism in patients without UTMs $[20,22]$. Study populations included children only $[13,16,17,22,24]$, both adults and children of either sex $[18,19,23]$, or only adult women [21]. In a quote of the studies, the authors had not specified the ethnic group of the patients $[13,16,19,20,23]$.

Table 2 describes the genetic investigation of patients with UTI susceptibility. The frequency of HSPA1B 1267A $>\mathrm{G}$, CXCR1 217C>G and CXCR1 2608G>C gene allele was 
TABLE 1: Summary of the characteristics of the included studies investigating the polymorphisms and/or mRNA or protein expression assessment in patients with recurrent urinary tract infections (CXCR: IL-8 receptor; HSPA1B: Heat shock protein 72; TGF: Transforming growth factor; TIRAP: TIR domain-containing adapter protein; TLR: Toll-like receptor; UTI: urinary tract infection; UTM: urinary tract malformation; VEGF: Vascular endothelial growth factor; VUR: vesicoureteral reflux).

\begin{tabular}{|c|c|c|c|c|c|c|}
\hline Genes & Polymorphisms & Gene expression & Patient categories & Ethnicity (country) & $\begin{array}{l}\text { Urological } \\
\text { malformations } \\
\text { included }\end{array}$ & References \\
\hline HSPA1B & $1267 A>G$ & - & Children & Hungarian & VUR & {$[17]$} \\
\hline \multirow{5}{*}{ CXCR1 } & - & + & Children & (Sweden) & \multirow{3}{*}{ VUR } & {$[13,16]$} \\
\hline & $217 \mathrm{C}>\mathrm{G}$ & + & & \multirow{2}{*}{ Caucasians } & & \multirow{2}{*}[18]{} \\
\hline & $2608 \mathrm{G}>\mathrm{C}$ & + & Children and adults & & & \\
\hline & - & + & & (Sweden) & & {$[19]$} \\
\hline & - & + & Pre-menopausal women & (Spain) & - & {$[20]$} \\
\hline \multirow{2}{*}{ CXCR2 } & - & + & Pre-menopausal women & (Spain) & - & {$[20]$} \\
\hline & - & + & Children & (Sweden) & VUR & {$[13,16]$} \\
\hline TLR1 & $1805 \mathrm{G}>\mathrm{T}$ & - & Adult women & Caucasian & UTM & {$[21]$} \\
\hline \multirow{2}{*}{ TLR2 } & \multirow{2}{*}{$2258 \mathrm{G}>\mathrm{A}$} & - & Children & Turkish & - & {$[22]$} \\
\hline & & - & Adult women & Caucasian & UTM & {$[21]$} \\
\hline \multirow{4}{*}{ TLR4 } & $896 \mathrm{~A}>\mathrm{G}$ & - & \multirow{2}{*}{ Adult women } & \multirow{2}{*}{ Caucasian } & \multirow{2}{*}{ UTM } & \multirow{2}{*}[21]{} \\
\hline & $1196 \mathrm{C}>\mathrm{T}$ & - & & & & \\
\hline & $896 A>G$ & - & Children & Hungarian & \multirow{2}{*}{ VUR } & {$[17]$} \\
\hline & - & + & Mainly children & (Sweden) & & {$[23]$} \\
\hline TRIF & $9 \mathrm{~A}>\mathrm{G}$ & + & Mainly children & (Sweden) & VUR & {$[23]$} \\
\hline TRAM & - & + & Mainly children & (Sweden) & VUR & {$[23]$} \\
\hline MyD88 & - & + & Mainly children & (Sweden) & VUR & {$[23]$} \\
\hline SIGIRR & - & + & Mainly children & (Sweden) & VUR & {$[23]$} \\
\hline TLR5 & $1174 \mathrm{C}>\mathrm{T}$ & - & Adult women & Caucasian & UTM & {$[21]$} \\
\hline \multirow{2}{*}{ TIRAP } & $589 \mathrm{C}>\mathrm{T}$ & - & \multirow{2}{*}{ Adult women } & \multirow{2}{*}{ Caucasian } & \multirow{2}{*}{ UTM } & \multirow{2}{*}[21]{} \\
\hline & $558 \mathrm{C}>\mathrm{T}$ & - & & & & \\
\hline \multirow{2}{*}{ VEGF } & $460 \mathrm{~T}>\mathrm{C}$ & - & \multirow{2}{*}{ Children } & \multirow{2}{*}{ Korean } & \multirow{2}{*}{ VUR } & \multirow{2}{*}[24]{} \\
\hline & $405 \mathrm{G}>\mathrm{C}$ & - & & & & \\
\hline \multirow{3}{*}{ TGF- $\beta 1$} & $509 \mathrm{C}>\mathrm{T}$ & - & \multirow{3}{*}{ Children } & \multirow{3}{*}{ Korean } & \multirow{3}{*}{ VUR } & \multirow{3}{*}[24]{} \\
\hline & $800 \mathrm{G}>\mathrm{A}$ & - & & & & \\
\hline & $869 \mathrm{~T}>\mathrm{C}$ & - & & & & \\
\hline
\end{tabular}

higher in patients with recurrent UTI than in control groups. In particular, the OR of an HSPA1B 1267A $>$ G polymorphism was 3 times higher in patients with recurrent UTIs. The study included patients with VUR of varied severity. No information is available on patients without VUR for both HSPAIB and CXCR1 polymorphisms [17, 19]. The OR of the TLR1 1805G>T gene polymorphism was lower in patients with pyelonephritis and comparable to those with cystitis than in controls. This population study included patients with urinary tract malformations [21]. The OR of TLR2 2258A allele was 3.1 times higher in children with recurrent UTIs, without VUR, than in controls [22]. Moreover, the OR of TLR2 2258A allele was not more significant in adult women with UTIs, including those with UTM, than in controls [21]. The frequency and OR of the TLR4 896A>G gene polymorphism were lower in patients with recurrent cystitis than in controls. The present study included patients and controls with urinary tract malformations [21]. Moreover, the frequency of a TLR4 896A>G gene polymorphism was slightly lower although statistically comparable to patients without VUR and controls. On the contrary, the OR was twice as high in patients, including those with VUR, than in controls [17]. The OR of the TLR4 1196C $>$ T polymorphism was lower in patients with recurrent cystitis than in controls and comparable to patients with APN and controls. The TLR5 $1174 \mathrm{C}>\mathrm{T}$ polymorphism was higher in patients with recurrent cystitis and comparable to patients with APN and controls, including patients with UTMs [21]. The frequency of the VEGF 460T >C polymorphism was higher in patients with UTI, including those with VUR, than in controls. Therefore, the frequency was comparable in patients without VUR but not with controls. Furthermore, the frequency of TGF- $\beta 1-509 \mathrm{C}>\mathrm{T}$ and $-800 \mathrm{G}>\mathrm{A}$ polymorphisms were lower in patients with UTI, including those with VUR, than in controls. The frequency was comparable between patients with UTI, without VUR, but not with controls [24]. 
TABLE 2: Comparison of the genotype frequencies for each polymorphism studied in patients with recurrent urinary tract infection and in controls. (CXCR: IL-8 receptor; HSPA1B: Heat shock protein 72; NS: not significant; PS: pyelonephritis; TGF: Transforming growth factor; TIRAP: TIR domain-containing adapter protein; TLR: Toll-like receptor; UTM: urinary tract malformations; VEGF: Vascular endothelial growth factor).

\begin{tabular}{|c|c|c|c|c|c|c|c|}
\hline Gene & Polymorphisms & $\begin{array}{l}\text { Urological condition also included } \\
\text { (infection type) }\end{array}$ & $\begin{array}{l}\text { Patients/controls } \\
(\mathrm{N} / \mathrm{N})\end{array}$ & Risk allele & OR $(95 \% \mathrm{CI})$ & $P$ value & References \\
\hline HSPA1B & $1267 \mathrm{~A}>\mathrm{G}$ & VUR & $103 / 235$ & $1267 \mathrm{G}$ & $3.37(1.04-10.93)$ & .036 & {$[17]$} \\
\hline \multirow{2}{*}{ CXCR1 } & $217 \mathrm{C}>\mathrm{G}$ & VUR, (Pyelonephritis) & $60 / 226$ & $217 \mathrm{G}$ & - & .0007 & \multirow{2}{*}[18]{} \\
\hline & $2608 \mathrm{G}>\mathrm{C}$ & VUR, (Pyelonephritis) & $60 / 226$ & $2608 \mathrm{C}$ & - & $<.001$ & \\
\hline \multirow{2}{*}{ TLR1 } & \multirow{2}{*}{$1805 \mathrm{G}>\mathrm{T}$} & UTM, (Pyelonephritis) & $281 / 286$ & $1805 \mathrm{G}$ & $0.53(0.29-0.96)$ & .035 & \multirow{2}{*}[21]{} \\
\hline & & UTM, (Recurrent cystitis) & $303 / 286$ & - & $0.73(0.46-1.17)$ & NS & \\
\hline \multirow{3}{*}{ TLR2 } & \multirow{3}{*}{$2258 \mathrm{G}>\mathrm{A}$} & - & $124 / 116$ & $2258 \mathrm{~A}$ & $3.14(1.53-6.44)$ & .001 & {$[22]$} \\
\hline & & UTM, (Pyelonephritis) & $329 / 316$ & - & $0.93(0.48-1.81)$ & NS & \multirow{2}{*}[21]{} \\
\hline & & UTM, (Recurrent cystitis) & $337 / 316$ & - & $0.83(0.42-1.63)$ & NS & \\
\hline \multirow{6}{*}{ TLR4 } & \multirow{4}{*}{$896 \mathrm{~A}>\mathrm{G}$} & UTM, (Pyelonephritis) & $318 / 313$ & - & $1.10(0.69-1.75)$ & NS & \multirow{2}{*}[21]{} \\
\hline & & UTM, (Recurrent cystitis) & $334 / 313$ & $896 \mathrm{~A}$ & $0.54(0.32-0.93)$ & .025 & \\
\hline & & VUR & $103 / 235$ & $896 \mathrm{G}$ & $2.19(1.05-4.57)$ & .034 & \multirow{4}{*}[21]{} \\
\hline & & - & $53 / 235$ & - & $0.33(0.10-1.12)$ & .067 & \\
\hline & \multirow{2}{*}{$1196 \mathrm{C}>\mathrm{T}$} & UTM, (Pyelonephritis) & $320 / 316$ & - & $1.10(0.69-1.75)$ & NS & \\
\hline & & UTM, (Recurrent cystitis) & $338 / 316$ & $1196 \mathrm{C}$ & $0.59(0.35-0.998)$ & .049 & \\
\hline TRIF & $9 \mathrm{~T}>9$ & VUR & $12 / 11$ & - & - & NS & {$[23]$} \\
\hline \multirow{2}{*}{ TLR5 } & \multirow{2}{*}{$1174 \mathrm{C}>\mathrm{T}$} & UTM, (Pyelonephritis) & $320 / 315$ & - & $1.17(0.17-2.09)$ & NS & \multirow{2}{*}[21]{} \\
\hline & & UTM, (Recurrent cystitis) & $337 / 315$ & $1174 \mathrm{~T}$ & $1.81(1.00-3.08)$ & .030 & \\
\hline \multirow{4}{*}{ TIRAP } & \multirow{2}{*}{$539 \mathrm{C}>\mathrm{T}$} & UTM, (Pyelonephritis) & $318 / 314$ & - & $0.86(0.61-1.23)$ & NS & \multirow{4}{*}[21]{} \\
\hline & & UTM, (Recurrent cystitis) & $338 / 314$ & - & $0.88(0.62-1.24)$ & NS & \\
\hline & \multirow{2}{*}{$558 \mathrm{C}>\mathrm{T}$} & UTM, (Pyelonephritis) & $317 / 313$ & - & $1.06(0.77,1.46)$ & NS & \\
\hline & & UTM, (Recurrent cystitis) & $329 / 313$ & - & $1.30(0.95,1.78)$ & NS & \\
\hline \multirow{4}{*}{ VEGF } & \multirow{2}{*}{$460 \mathrm{~T}>\mathrm{C}$} & VUR & $63 / 71$ & $460 \mathrm{C}$ & \multirow{2}{*}{-} & $<.05$ & \multirow{4}{*}[24]{} \\
\hline & & - & $18 / 71$ & - & & NS & \\
\hline & \multirow{2}{*}{$405 \mathrm{G}>\mathrm{C}$} & VUR & $71 / 82$ & - & \multirow{2}{*}{ - } & NS & \\
\hline & & - & $19 / 82$ & - & & NS & \\
\hline \multirow{6}{*}{ TGF- $\beta 1$} & \multirow{2}{*}{$-509 \mathrm{C}>\mathrm{T}$} & VUR & $78 / 80$ & $-509 C$ & \multirow[t]{2}{*}{ - } & $<.05$ & \\
\hline & & - & $21 / 80$ & - & & NS & \\
\hline & $-800 \mathrm{G}>\mathrm{A}$ & VUR & $79 / 89$ & $-800 \mathrm{G}$ & - & $<.05$ & \\
\hline & -0000 & - & $22 / 89$ & - & & NS & {$[24]$} \\
\hline & $869 \mathrm{~T}>\mathrm{C}$ & VUR & $77 / 85$ & - & - & NS & \\
\hline & & - & $20 / 85$ & - & & NS & \\
\hline
\end{tabular}

Table 3 summarizes the studies concerning protein expression in patients with susceptibility to UTI. Patients with recurring UTIs showed lower expression levels of CXCR1 than control patients did. The study included patients with VUR of various degrees $[13,16,18,19]$. Smithson et al., investigating premenopausal women with recurrent UTI but no VUR, showed that CXCR1 expression was comparable to controls. However, women had low expression levels of CXCR2 [20]. Ragnarsdattir et al. compared TLR4 and the TLR4 adaptor proteins TRIF and SIGIRR genes in children with asymptomatic bacteriurias, including those with VUR, with controls. The TLR4 and SIGIRR genes had reduced gene expression, whereas the TRIF gene had increased expression [23].
3.6. Risk of Bias in Included Studies. Table 4 summarizes the potential risks of bias for each study. One study completed an analysis of both genetic polymorphisms and expression of the CXCR1 gene [18]. Another study performed the expression of the TRIF gene, but the frequency of the TRIF polymorphism was performed in only one quote of these patients (71\% patients versus $46 \%$ controls) [23]. One study assessed the CXCR1 expression, but the frequency of the CXCR1 gene polymorphism was not estimated in the control individuals [20]. Ethnicity was reported in five out of nine studies [17, 18, 21, 22, 24]. Hardy-Weinberg equilibrium was assessed in 3 out of 5 studies [17, 21, 22]. In four studies, this assessment was not applicable $[16,18,20,23]$. One study, investigating for TGF- $\beta 1$ and VEGF polymorphisms, 
TABLE 3: Comparison of the gene expression of patients with recurrent urinary tract infection and controls. (CXCR: IL-8 receptors; MyD88: myeloid differentiation primary response gene 88; SIGIRR: single immunoglobulin domain-containing IL-1 receptor-related molecule; TLR: Toll-like receptor; TRAM: TIR domain-containing adaptor inducing IFN- $\beta$-related adaptor molecule; TRIF: TIR domain-containing adaptor inducing INF- $\beta$ ).

\begin{tabular}{|c|c|c|c|c|c|}
\hline Protein expression & Patients/controls (N/N) & Patient values (range or \pm SD) & Control value (range or $\pm \mathrm{SD}$ ) & $P$ & References \\
\hline \multirow{4}{*}{ CXCR1 } & $12 / 12$ & $0.33 \pm 0.23$ & $1.33 \pm 0.64$ & $<.05$ & {$[13,16]$} \\
\hline & $60 / 226$ & $-1.44[-6.52-(1.04)]^{*}$ & $0.28[-0.73-(2.15)]^{*}$ & $<.0001$ & {$[18]$} \\
\hline & $10 / 15$ & $70 \%(42 \%-96 \%)$ & $100 \%(77 \%-165 \%)$ & .0006 & {$[19]$} \\
\hline & $20 / 30$ & $118.9(102.7-158.9) \mathrm{AU}$ & $116.2(103.7-139.5) \mathrm{AU}$ & NS & {$[20]$} \\
\hline CXCR2 & $20 / 30$ & $14.9(12.82-17.23) \mathrm{AU}$ & $18.9(16.2-23.6) \mathrm{AU}$ & .002 & {$[20]$} \\
\hline TLR4 & \multirow{5}{*}{$17 / 24$} & $33.2(4.3-74.3)$ & $56.1(19.2-87.6)$ & .003 & \multirow{5}{*}[23]{} \\
\hline MyD88 & & $100.5(9.3-197.3)$ & $84.3(9.9-168.5)$ & NS & \\
\hline TRIF & & $139(34.5-315.1)$ & $85.1(12.4-171.5)$ & .02 & \\
\hline TRAM & & $107.9(32-262.9)$ & $101.7(39.8-269.2)$ & NS & \\
\hline SIGIRR & & $14.9(8.2-63.3)$ & $21.9(12.5-35.5)$ & .0005 & \\
\hline
\end{tabular}

Legend : ${ }^{*}$ : compared to a standard; AU: arbitrary unit.

did not clarify whether the patient had recurrent UTIs although its objective was to assess susceptibility to UTIs. These patients were enrolled at their first UTI [24]. One study concerning TLR4 gene expression investigated for primary and secondary bacteriurias [23]. In only one study, concerning the TLR2 gene polymorphism, patients had no urological malformations [22]. Two studies concerning the HSPA1B, TLR4, VEGF, and TGF- $\beta 1$ gene polymorphisms performed the statistical analysis in a subgroup of patients without VUR $[17,24]$.

\section{Discussion}

The first protection against a UTI involves physical barriers (unidirectional urinary flow), epithelial cells and the production of proteins that hinder bacteria adhesion [38]. The structural variability of host cell glycoconjugates characterizes pathogen recognition at mucosal sites. Subsequently, the oncoming inflammation activates the uroepitelial cells, which produce mediators of inflammation, until the pathogens are destroyed and eliminated. The functional chemokines and chemokine receptors are crucial for neutrophil recruitment and for neutrophil dependent bacterial clearance. Moreover, the neutrophil-mediated defense is essential for resistance to UTIs.

The inter-individual variability in cellular response may be responsible for variable clinical outcomes and may explain why certain individuals are susceptible to recurrent infections [38]. Susceptibility to UTIs is caused by inefficient bacterial clearance due to an impairment of the innate host defense, such as low chemokine receptor expression [16]. The neutrophils' functional state is influenced by the chemokine receptor expression of the urinary tract. Thus, the neutrophil and local environment of cytokine/chemokine/cell adhesion molecules, which govern the intensity and persistence of the host response, have been actively investigated [39].
Six out of 14 genes investigated in humans (HSPA1B, CXCR1 and 2, TLR1,2,4,5, SIGIRR, TRIF, TRAM, MyD88 TIRAP, VEGF, and TGF-1 $\beta$ ) may be associated with susceptibility to UTI recurrence in humans. In particular, the HSPA1B, CXCR1 \& 2 , TLR2, TLR4 and TGF- $\beta 1$ genes seem to be associated at various levels with an alteration of the host response to the UTI. The HSPA1B gene encodes a $70 \mathrm{kDa}$ heat shock protein (HSP) that is a member of the HSP70 family [17]. Patients with recurrent UTIs showed a high prevalence of the HSPA1B $1267 \mathrm{G}$ allele [17]. The CXCR1 gene encodes a human chemokine receptor gene for IL-8 chemokine [18]. Mutational inactivation of the CXCR1 causes both acute disease and chronic tissue damage in mice [40]. Cell surface CXCR1 expression and CXCR1specific mRNA levels were low in the neutrophils of both mice and children with recurrent UTIs [16]. Pyelonephritis prone children showed low expression levels of CXCR1 [23]. Patients susceptible to UTIs after the age of 15 years showed CXCR1 gene expression comparable to controls [20]. However, humans with recurrent UTI showed a high frequency of polymorphic allele (217G and 2608C) as well as reduced gene expression [18]. Moreover, CXCR2 expression in children aged 2-12 years at first manifestation of a UTI was comparable to controls [13]; whereas premenopausal women with recurrent UTI had lower CXCR2 expression than agematched controls [20]. These data seem to suggest that the CXCR1 and CXCR2 genes could be associated with early or late manifestation of susceptibility, respectively.

TLRs are a family of receptors that recognize pathogenassociated molecules, and whose activation leads to the transcription of appropriate host-defense genes and to the recruitment of leucocytes [21]. Tabel et al. showed that TLR2 2258A allele in children has been implicated in susceptibility to gram-positive pathogens [22], but not in adult women with UTI including those with UTMs [21]. However, genetic alteration of TLR4 signaling could modify the host unresponsiveness to a UTI towards asymptomatic bacteriuria $(\mathrm{ABU})$ rather than symptomatic pyelonephritis [41]. Children with asymptomatic bacteriuria expressed less 
TABLE 4: Methodological quality of each included study. The studies are listed according to their presentation along this review. (CXCR: IL-8 receptor; MyD88: myeloid differentiation primary response gene 88; NA: not applicable; SIGIRR: single immunoglobulin domaincontaining IL-1 receptor-related molecule; TLR: Toll-like receptor; TRAM: TIR domain-containing adaptor inducing IFN- $\beta$-related adaptor molecule; TRIF: TIR domain-containing adaptor inducing INF- $\beta$ ).

\begin{tabular}{|c|c|c|c|c|c|c|}
\hline Authors & Gene polymorphism(s) & $\begin{array}{l}\text { Protein }(\mathrm{s}) \\
\text { expression }\end{array}$ & Ethnicity & $\begin{array}{r}\text { Hardy- } \\
\text { Weinberg } \\
\text { equilibrium } \\
\end{array}$ & $\begin{array}{l}\text { UTI } \\
\text { recurrence }\end{array}$ & $\begin{array}{c}\text { Exclusion of } \\
\text { urinary tract } \\
\text { malformations }\end{array}$ \\
\hline Lundstedt et al. [18] & CXCR1 & CXCR1 & Caucasians & - & + & - \\
\hline Smithson et al. [20] & CXCR1 [Unavailable controls] & $\begin{array}{l}\text { CXCR1, } \\
\text { CXCR2 }\end{array}$ & - & NA & + & + \\
\hline Lundstedt et al. [19] & - & CXCR1 & - & NA & + & - \\
\hline Frendéus et al. $[13,16]$ & - & CXCR1 & - & NA & + & - \\
\hline Hawn et al. [21] & $\begin{array}{l}\text { TLR1, TLR2,TLR4, TLR5, } \\
\text { TIRAP }\end{array}$ & - & Caucasian & + & + & - \\
\hline Tabel et al. [22] & TLR2 & - & Turkish & + & + & - \\
\hline Karoly et al. [17] & TLR4, HSPA1B & - & Hungarian & + & + & - \\
\hline Ragnardosttir et al. [23] & $\begin{array}{l}\text { TRIF (assessed in a proportion } \\
\text { of patients) }\end{array}$ & $\begin{array}{l}\text { TLR4, MyD88, } \\
\text { TRIF, TRAM }\end{array}$ & - & NA & $\begin{array}{l}\text { [asymptomatic } \\
\text { bacteriurias] }\end{array}$ & - \\
\hline Yim et al. [24] & VEGF, TGF- $\beta 1$ & - & Korean & - & - & - \\
\hline
\end{tabular}

TLR4 than age-matched controls [23]. However, the TLR4 gene showed comparable frequency of allele and genotype $[17,21]$. Thus, the authors extended the investigation to TLR4 regulatory genes. In particular, the TRIF gene showed increased expression and SIGIRR at reduced expression levels [23]. Moreover, TGF- $\beta 1-509 \mathrm{~T}$ allele showed a protective role in predisposition to recurrent UTIs because they were less frequent in children with recurrent UTIs. TGF- $\beta 1$ appears to be a key cytokine involved in the regulation of cell proliferation, differentiation, extracellular matrix formation and immune response [24].

The available studies are heterogeneous for population study and thus difficult to compare with each other; they studied different ethnic groups, included patients with urinary tract malformations of various types and degree. They are limited in number which makes a metaanalytical study impossible. However, the assessment of protein expression was not performed for most of the genes studied. Therefore, CXCR1 is the most important gene that seems to be involved in susceptibility to recurrent UTI. A reduced CXCR1 expression was observed in both children and adults with recurrent UTI. It is likely that these studies on the CXCR1 gene may be biased because of inclusion of patients with VUR $[16,18]$. Other genes could be associated with UTI susceptibility: polymorphisms of HSPA1B giving susceptibility [17] and TGF-1 $\beta$ giving protection [24], although these studies could be biased by inclusion of patients with VUR. Limited information is available on CXCR2, TLR2 and TLR4 pathways to arrive at any conclusion on UTI susceptibility in humans. However, TLR4 expression was reduced in children with recurrent UTIs [23], whereas its $1196 \mathrm{C}>\mathrm{T}$ polymorphism was shown to be protective in adult women with recurrent cystitis [21]. These studies included patients with UTMs. The frequency of HSPA1B (1267A>G), CXCR1 (217C > G, 2608G >C), TLR4
(1196C $>$ T), TLR5 $(1174 \mathrm{C}>\mathrm{T})$, VEGF $(460 \mathrm{~T}>\mathrm{C})$ and TGF$\beta 1(-509 \mathrm{C}>\mathrm{T}$ and $-800 \mathrm{G}>\mathrm{A})$ polymorphisms were different between patients with recurrent UTI and controls, but the study population included subjects with UTMs. In this context, TGF- $\beta 1$ protected from UTI recurrences in patients with VUR. Finally, only three studies, investigating TLR2, TLR4, VEGF, and TGF $\beta 1$ polymorphisms, were conducted on patients without VUR [17, 21, 24]; all but one (TLR2 $2258 \mathrm{G}>\mathrm{A}$ in children) showed no significant associations. In particular, the frequency of TLR2 2258A allele was high in children susceptible to UTIs [22]. These data have not been recently confirmed in adult women with UTI, including individuals with UTM [21]. The inclusion of patients of different ages and the presence of UTM make it impossible to make a comparison between the two studies and offer conclusive remarks.

In conclusion, the pathophysiological background of susceptibility to recurrent UTIs remains to be completely clarified, taking into account that multiple factors, such as gene-gene and gene-environmental interactions could be involved. The kidney may act as a host where clusters of bacteria persist as quiescent reservoirs surviving the immune response and resisting antibiotic attacks. Moreover, recent findings suggest that the genome of bacterial strains are associated with either asymptomatic, commensal-like strains that cause asymptomatic bacteriurias or with symptomatic infections [42], suggesting that the simple colonization or an infection can also be related to an interaction between the bacterial gene-patient gene relationship. Recent advances have suggested that a deregulation of candidate genes in humans could possibly predispose patients to recurrent UTI. The recognition of a genetic component in UTI recurrences will make it possible to diagnose at-risk adults and to predict genetic recurrences in their offspring. Marked differences in APN-associated morbidity between relatives of APN-prone 
patients and the relatives of control subjects suggested that inheritance could be autosomal involving one or more genes [18]. For example, the combinations of polymorphisms of CXCR1 and TGF- $\beta 1$ in the same individual could have additional effects on susceptibility. The treatment options with prophylactic antibiotics to prevent recurrent UTIs in children remain of doubtful usefulness [43]. The identification of susceptible patients could enable novel strategies in the management of recurrent UTIs. Antagonists and agonists of candidate gene products could manipulate host defense mechanisms, offering new therapeutic options to physicians treating UTI [44].

\section{Abbreviations}

APN: Acute pyelonephritis

UTI: Urinary tract infection

UTM: Urinary tract malformation.

\section{References}

[1] J. C. Craig, "Urinary tract infection: new perspectives on a common disease," Current Opinion in Infectious Diseases, vol. 14, no. 3, pp. 309-313, 2001.

[2] M. Nuutinen and M. Uhari, "Recurrence and follow-up after urinary tract infection under the age of 1 year," Pediatric Nephrology, vol. 16, no. 1, pp. 69-72, 2001.

[3] N. Le Saux, B. Pham, and D. Moher, "Evaluating the benefits of antimicrobial prophylaxis to prevent urinary tract infections in children: a systematic review," Canadian Medical Association Journal, vol. 163, no. 5, pp. 523-529, 2000.

[4] U. Jodal and J. Winberg, "Pyelonephritis. Report of the 4th International Symposium, Goteborg, Sweden 1986," Pediatric Nephrology, vol. 1, no. 2, pp. 248-252, 1987.

[5] W. J. Hopkins, J. Elkahwaji, C. Kendziorski, A. R. Moser, P. M. Briggs, and K. A. Suhs, "Quantitative trait loci associated with susceptibility to bladder and kidney infections induced by Escherichia coli in female $\mathrm{C} 3 \mathrm{H} / \mathrm{HeJ}$ mice," Journal of Infectious Diseases, vol. 199, no. 3, pp. 355-361, 2009.

[6] G. Finer and D. Landau, "Pathogenesis of urinary tract infections with normal female anatomy," Lancet Infectious Diseases, vol. 4, no. 10, pp. 631-635, 2004.

[7] B. Ragnarsdóttir, H. Fischer, G. Godaly, et al., "TLR- and CXCR1-dependent innate immunity: insights into the genetics of urinary tract infections," European Journal of Clinical Investigation, vol. 38, supplement 2, pp. 12-20, 2008.

[8] W. J. Hopkins, D. T. Uehling, and D. S. Wargoski, "Evaluation of a familial predisposition to recurrent urinary tract infections in women," American Journal of Medical Genetics, vol. 83, no. 5, pp. 422-424, 1999.

[9] C. M. Stauffer, B. van der Weg, R. Donadini, G. P. Ramelli, S. Marchand, and M. G. Bianchetti, "Family history and behavioral abnormalities in girls with recurrent urinary tract infections: a controlled study," Journal of Urology, vol. 171, no. 4, pp. 1663-1665, 2004.

[10] D. Scholes, T. M. Hooton, P. L. Roberts, A. E. Stapleton, K. Gupta, and W. E. Stamm, "Risk factors for recurrent urinary tract infection in young women," Journal of Infectious Diseases, vol. 182, no. 4, pp. 1177-1182, 2000.

[11] W. J. Hopkins, A. Gendron-Fitzpatrick, D. O. McCarthy, J. E. Haine, and D. T. Uehling, "Lipopolysaccharide-responder and nonresponder $\mathrm{C} 3 \mathrm{H}$ mouse strains are equally susceptible to an induced Escherichia coli urinary tract infection," Infection and Immunity, vol. 64, no. 4, pp. 1369-1372, 1996.

[12] L. Hagberg, R. Hull, S. Hull, et al., "Difference in susceptibility to gram-negative urinary tract infection between $\mathrm{C} 3 \mathrm{H} / \mathrm{HeJ}$ and $\mathrm{C} 3 \mathrm{H} / \mathrm{HeN}$ mice," Infection and Immunity, vol. 46, no. 3, pp. 839-844, 1984.

[13] B. Frendéus, G. Godaly, L. Hang, D. Karpman, and C. Svanborg, "Interleukin-8 receptor deficiency confers susceptibility to acute pyelonephritis," Journal of Infectious Diseases, vol. 183, pp. S56-S60, 2001.

[14] L. Hagberg, D. E. Briles, and C. S. Edén, "Evidence for separate genetic defects in $\mathrm{C} 3 \mathrm{H} / \mathrm{HeJ}$ and $\mathrm{C} 3 \mathrm{HeB} / \mathrm{FeJ}$ mice, that affect susceptibility to gram-negative infections," Journal of Immunology, vol. 134, no. 6, pp. 4118-4122, 1985.

[15] C. S. Edén, R. Kulhavy, S. Mårild, S. J. Prince, and J. Mestecky, "Urinary immunoglobulins in healthy individuals and children with acute pyelonephritis," Scandinavian Journal of Immunology, vol. 21, no. 4, pp. 305-313, 1985.

[16] B. Frendéus, G. Godaly, L. Hang, D. Karpman, A.-C. Lundstedt, and C. Svanborg, "Interleukin 8 receptor deficiency confers susceptibility to acute experimental pyelonephritis and may have a human counterpart," Journal of Experimental Medicine, vol. 192, no. 6, pp. 881-890, 2000.

[17] E. Karoly, A. Fekete, N. F. Banki, et al., "Heat shock protein 72 (HSPA1B) gene polymorphism and toll-like receptor (TLR) 4 mutation are associated with increased risk of urinary tract infection in children," Pediatric Research, vol. 61, no. 3, pp. 371-374, 2007.

[18] A.-C. Lundstedt, S. McCarthy, M. C. U. Gustafsson, et al., "A genetic basis of susceptibility to acute pyelonephritis," PLoS One, vol. 2, no. 9, article e825, 2007.

[19] A.-C. Lundstedt, I. Leijonhufvud, B. Ragnarsdottir, D. Karpman, B. Andersson, and C. Svanborg, "Inherited susceptibility to acute pyelonephritis: a family study of urinary tract infection," Journal of Infectious Diseases, vol. 195, no. 8, pp. 1227-1234, 2007.

[20] A. Smithson, M. R. Sarrias, J. Barcelo, et al., "Expression of interleukin-8 receptors (CXCR1 and CXCR2) in premenopausal women with recurrent urinary tract infections," Clinical and Diagnostic Laboratory Immunology, vol. 12, no. 12, pp. 1358-1363, 2005.

[21] T. R. Hawn, D. Scholes, S. S. Li, et al., "Toll-like receptor polymorphisms and susceptibility to urinary tract infections in adult women," PLoS ONE, vol. 4, no. 6, article e5990, 2009.

[22] Y. Tabel, A. Berdeli, and S. Mir, "Association of TLR2 gene Arg753Gln polymorphism with urinary tract infection in children," International Journal of Immunogenetics, vol. 34, no. 6, pp. 399-405, 2007.

[23] B. Ragnarsdóttir, M. Samuelsson, M. C. U. Gustafsson, I. Leijonhufvud, D. Karpman, and C. Svanborg, "Reduced Tolllike receptor 4 expression in children with asymptomatic bacteriuria," Journal of Infectious Diseases, vol. 196, no. 3, pp. 475-484, 2007.

[24] H. E. Yim, I. S. Bae, K. H. Yoo, Y. S. Hong, and J. W. Lee, "Genetic control of VEGF and TGF- $\beta 1$ gene polymorphisms in childhood urinary tract infection and vesicoureteral reflux," Pediatric Research, vol. 62, no. 2, pp. 183-187, 2007.

[25] J. C. T. Lu, S. G. Coca, U. D. Patel, L. Cantley, and C. R. Parikh, "Searching for genes that matter in acute kidney injury: a systematic review," Clinical Journal of the American Society of Nephrology, vol. 4, no. 6, pp. 1020-1031, 2009.

[26] S. J. Chanock, T. Manolio, M. Boehnke, et al., "Replicating genotype-phenotype associations," Nature, vol. 447, no. 7145, pp. 655-660, 2007. 
[27] L. Artifoni, S. Negrisolo, G. Montini, et al., "Interleukin-8 and CXCR1 receptor functional polymorphisms and susceptibility to acute pyelonephritis," Journal of Urology, vol. 177, no. 3, pp. 1102-1106, 2007.

[28] M. Bajpai, A. Pratap, C. Somitesh, and J. Tyagi, "Angiotensin converting enzyme gene polymorphism in Asian Indian children with congenital uropathies," Journal of Urology, vol. 171, no. 2 I, pp. 838-840, 2004.

[29] S. J. Cho and S. J. Lee, "ACE gene polymorphism and renal scar in children with acute pyelonephritis," Pediatric Nephrology, vol. 17, no. 7, pp. 491-495, 2002.

[30] S. A. Cotton, R. A. Gbadegesin, S. Williams, et al., "Role of TGF- $\beta 1$ in renal parenchymal scarring following childhood urinary tract infection," Kidney International, vol. 61, no. 1, pp. 61-67, 2002.

[31] H. Erdogan, S. Mir, E. Serdaroglu, A. Berdeli, and N. Aksu, "Is ACE gene polymorphism a risk factor for renal scarring with low-grade reflux?” Pediatric Nephrology, vol. 19, no. 7, pp. 734-737, 2004.

[32] A. Ece, S. Tekes, F. Gürkan, M. Bilici, and T. Budak, "Polymorphisms of the angiotensin converting enzyme and angiotensin II type 1 receptor genes and renal scarring in nonuropathic children with recurrent urinary tract infection," Nephrology, vol. 10, no. 4, pp. 377-381, 2005.

[33] R. A. Gbadegesin, S. A. Cotton, C. J. Watson, P. E. C. Brenchley, and N. J. A. Webb, "Association between ICAM-1 Gly-Arg polymorphism and renal parenchymal scarring following childhood urinary tract infection," International Journal of Immunogenetics, vol. 33, no. 1, pp. 49-53, 2006.

[34] K. Hohenfellner, T. E. Hunley, R. Brezinska, et al., "ACE I/D gene polymorphism predicts renal damage in congenital uropathies," Pediatric Nephrology, vol. 13, no. 6, pp. 514-518, 1999.

[35] P. Kimball and F. Reid, "Tumor necrosis factor $\beta$ gene polymorphisms associated with urinary tract infections after renal transplantation," Transplantation, vol. 73, no. 7, pp. 1110-1112, 2002.

[36] R. Pardo, S. Málaga, E. Coto, et al., "Renin-angiotensin system polymorphisms and renal scarring," Pediatric Nephrology, vol. 18, no. 2, pp. 110-114, 2003.

[37] A. Yoneda, S. Cascio, T. Oue, B. Chertin, and P. Puri, "Risk factors for the development of renal parenchymal damage in familial vesicoureteral reflux," Journal of Urology, vol. 168, no. 4 II, pp. 1704-1707, 2002.

[38] R. H. Mak and H.-J. Kuo, "Pathogenesis of urinary tract infection: an update," Current Opinion in Pediatrics, vol. 18, no. 2, pp. 148-152, 2006.

[39] N. J. A. Webb and P. E. C. Brenchley, "Cytokines and cell adhesion molecules in the inflammatory response during acute pyelonephritis," Nephron Experimental Nephrology, vol. 96, no. 1, pp. e1-e6, 2004.

[40] G. Godaly, G. Bergsten, L. Hang, et al., "Neutrophil recruitment, chemokine receptors, and resistance to mucosal infection," Journal of Leukocyte Biology, vol. 69, no. 6, pp. 899-906, 2001.

[41] H. Fischer, M. Yamamoto, S. Akira, B. Beutler, and C. Svanborg, "Mechanism of pathogen-specific TLR4 activation in the mucosa: fimbriae, recognition receptors and adaptor protein selection," European Journal of Immunology, vol. 36, no. 2, pp. 267-277, 2006.

[42] V. Hancock, A. S. Seshasayee, D. W. Ussery, N. M. Luscombe, and P. Klemm, "Transcriptomics and adaptive genomics of the asymptomatic bacteriuria Escherichia coli strain 83972,"
Molecular Genetics and Genomics, vol. 279, no. 5, pp. 523-534, 2008.

[43] G. Williams and J. C. Craig, "Prevention of recurrent urinary tract infection in children," Current Opinion in Infectious Diseases, vol. 22, no. 1, pp. 72-76, 2009.

[44] J. E. Scherberich and A. Hartinger, "Impact of Toll-like receptor signalling on urinary tract infection," International Journal of Antimicrobial Agents, vol. 31, pp. S9-S14, 2008. 

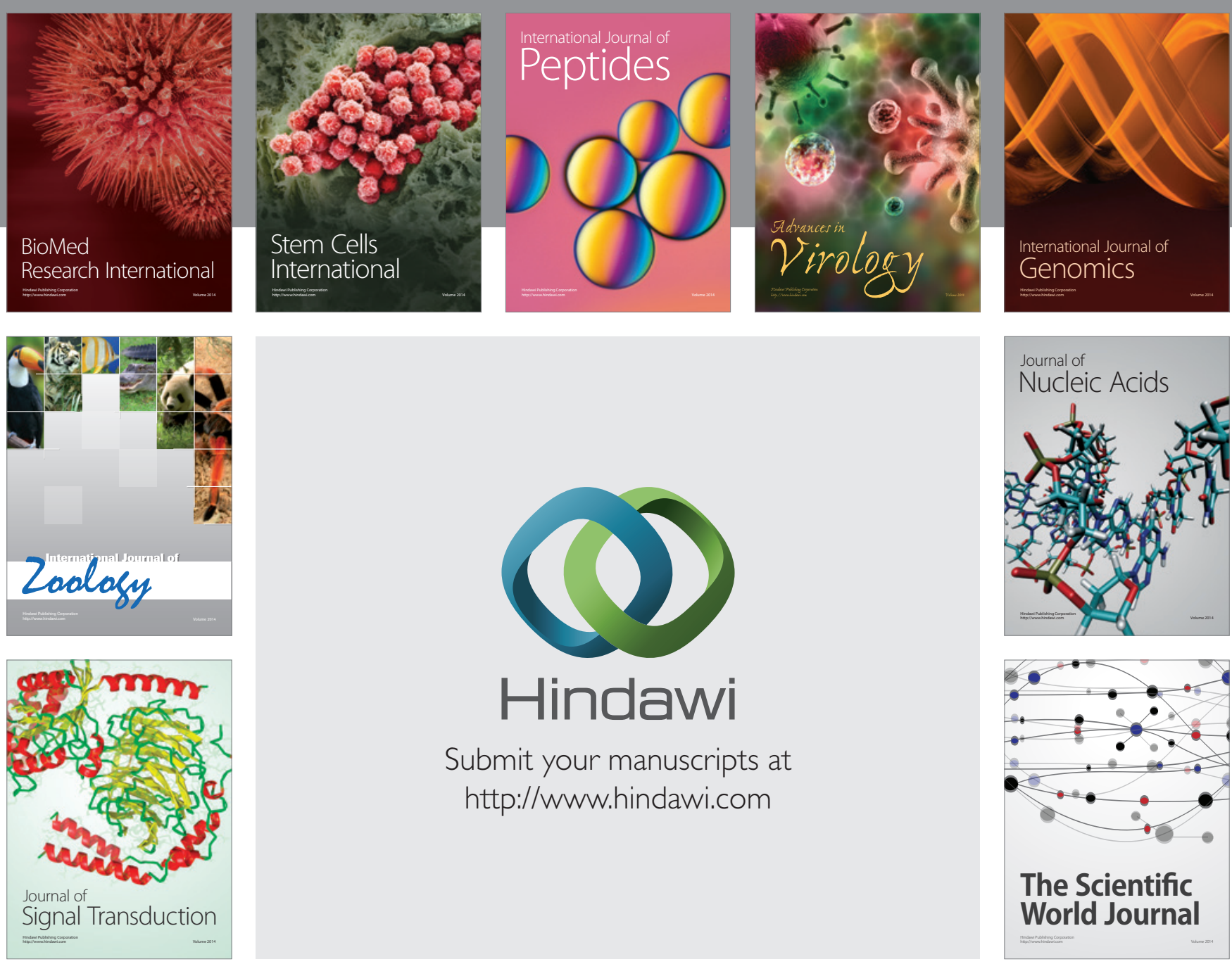

Submit your manuscripts at

http://www.hindawi.com
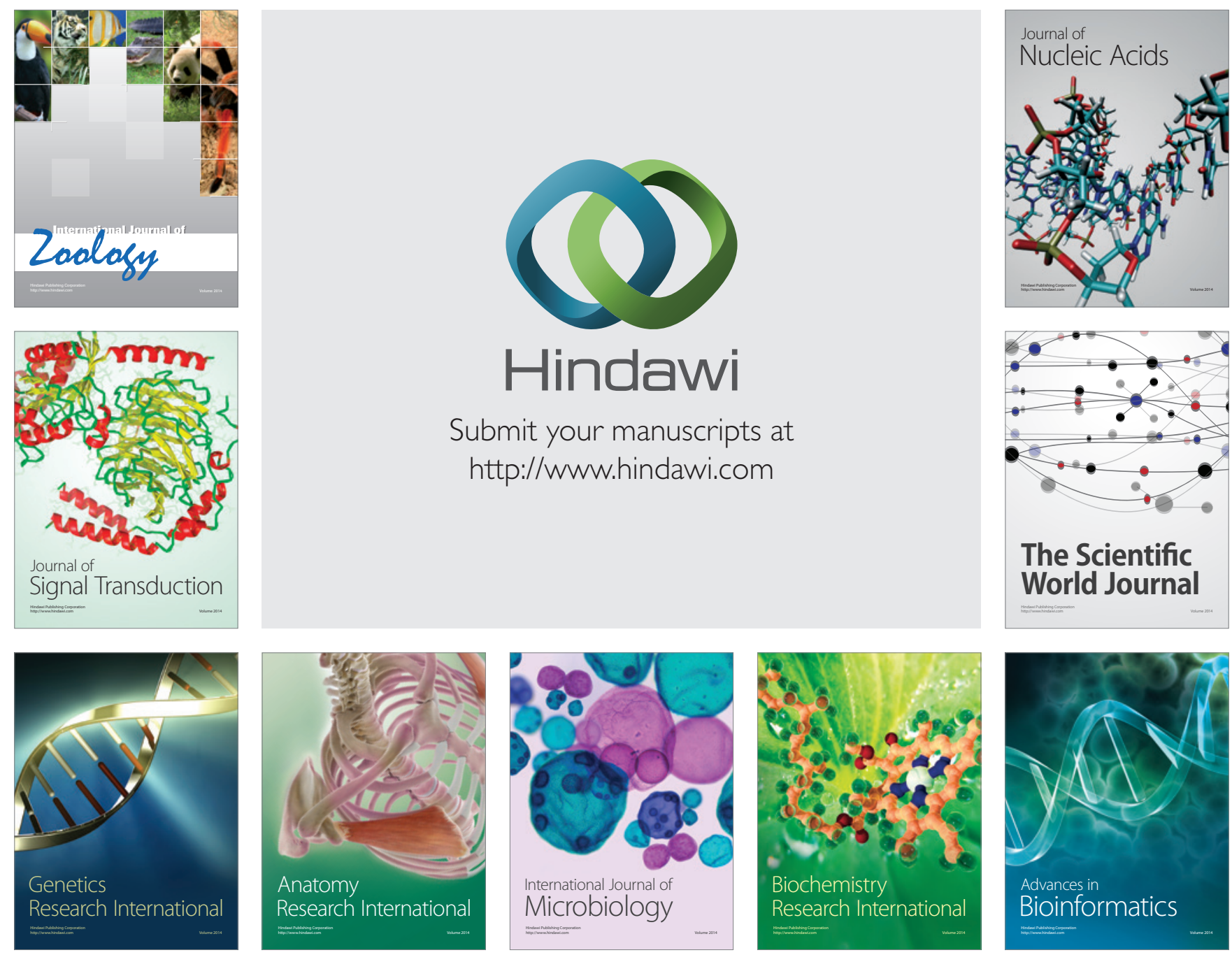

The Scientific World Journal
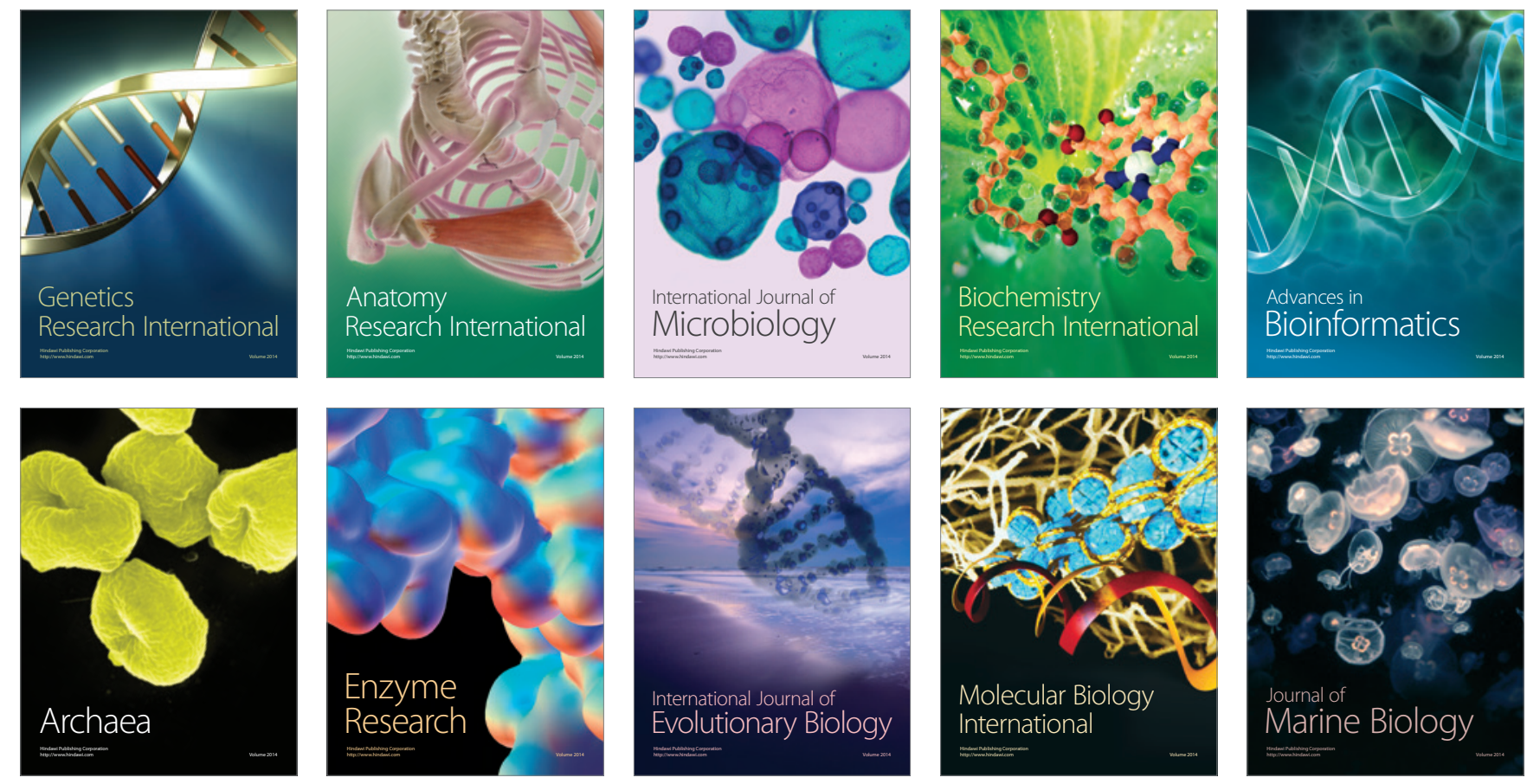